\title{
Ribonucleotide reductase subunit M1 assessed by quantitative double-fluorescence immunohistochemistry predicts the efficacy of gemcitabine in biliary tract carcinoma
}

\author{
JUN NAKAMURA ${ }^{1}$, NAOHIKO KOHYA ${ }^{1}$, KEITA KAI ${ }^{1,2}$, KAZUMA OHTAKA ${ }^{1}$, \\ KAZUYOSHI HASHIGUCHI ${ }^{1}$, MASATSUGU HIRAKI ${ }^{1}$, YOSHIHIKO KITAJIMA ${ }^{1}$, \\ OSAMU TOKUNAGA ${ }^{2}$, HIROKAZU NOSHIRO ${ }^{1}$ and KOHJI MIYAZAKI $^{1}$ \\ Departments of ${ }^{1}$ Surgery and ${ }^{2}$ Pathology and Biodefence, Saga University \\ Faculty of Medicine, 5-1-1 Nabeshima, Saga 849-8501, Japan
}

Received March 22, 2010; Accepted May 7, 2010

DOI: 10.3892/ijo_00000735

\begin{abstract}
Gemcitabine is a commonly used chemotherapeutic agent for advanced biliary tract carcinoma (BTC), although its efficacy is insufficient. Therefore, it is essential to establish new diagnostic methods, which can predict responders before the treatment. The aim of this study is to identify the most reliable chemoresistance marker to gemcitabine in BTC among the 4 molecules (hENT1, dCK, RRM1 and RRM2) involved in gemcitabine metabolism. The expression of 4 molecules were investigated in 5 BTC cell lines, and correlated with gemcitabine sensitivity. RRM1 protein was also assessed by quantitative double-fluorescence immunohistochemistry (qDFIHC) in 10 patients with unresectable or recurrent BTC who received gemcitabine-based chemotherapy. RRM1 and RRM2 protein strongly correlated with the $\mathrm{IC}_{50}$ value for gemcitabine in BTC cell lines ( $\mathrm{R}=0.935,0.771$, respectively). In addition, patients with low RRM1 were significantly more sensitive to gemcitabine ( $\mathrm{p}=0.033$ ), and their survival was significantly better than patients with high RRM1 ( $\mathrm{p}=0.001)$. In conclusion, RRM1 particularly in protein level is a reliable marker for gemcitabine resistance in BTC. Furthermore, qDFIHC is a useful method for the assessment of RRM1 protein, in order to design a tailor-made chemotherapeutic regimen for BTC patients.
\end{abstract}

\section{Introduction}

Biliary tract carcinoma (BTC), including gallbladder carcinoma and intra- and extra-hepatic bile duct carcinoma, is relatively

Correspondence to: Dr Kohji Miyazaki, Department of Surgery, Saga University, Faculty of Medicine, 5-1-1 Nabeshima, Saga 849-8501, Japan

E-mail: miyazak2@cc.saga-u.ac.jp

Key words: gemcitabine, chemoresistance, ribonucleotide reductase subunit M1, quantitative double-fluorescence immunohistochemistry, biliary tract carcinoma rare, but the incidence of BTC has increased markedly in Japan over the past several decades (1). Although a complete surgical resection is the only curative modality, most patients are not eligible for surgery because of the advanced stage of disease at diagnosis. Moreover, even patients who underwent a surgical resection, eventually have a recurrence of the disease (2-4). The outcome of patients with unresectable or recurrent BTC is dismal, and their median survival is usually $<1$ year. Therefore, most patients with unresectable or recurrent BTC are possible candidates for palliative chemotherapy. To date, only 1 randomized trial has demonstrated that combination chemotherapy may improve the survival and quality of life in patients with advanced BTC in comparison to the best supportive care (5). However, no standard chemotherapy regimen for advanced BTC has been established. Several phase II trials with new chemotherapeutic agents, such as gemcitabine (6$10)$, capecitabine $(11)$, oxaliplatin $(12)$, or S-1 $(13,14)$ have demonstrated tumor response in $\sim 15-35 \%$ of patients treated with single agents, and in $20-40 \%$ of patients treated with their combinations (15-24). Among them, gemcitabine has shown promising activity against advanced BTC, and has been commonly used for patients with unresectable or recurrent BTC in Japan.

Gemcitabine (2'2-difluorodeoxycytidine, $\mathrm{dFdC}$ ) is a specific analogue of deoxycytidine. It is a novel anticancer agent that has significant efficacy in several solid tumors, including BTC (25-29). Gemcitabine is transported into the cell mostly by human equilibrative nucleoside transporter-1 (hENT1) (30), phosphorylated by deoxycytidine kinase (dCK) to its monophosphate form (dFdCMP) (31), and then is further phosphorylated to the active triphosphate form. The subsequent incorporation of gemcitabine triphosphate ( $\mathrm{dFdCTP}$ ) into DNA, which causes the addition of a single deoxynucleotide and chain termination, is a major mechanism underlying the cytotoxicity of gemcitabine (32). In addition, the diphosphate metabolite of gemcitabine ( $\mathrm{dFdCDP})$ is also reported to inhibit ribonucleotide reductase (RR), thereby causing a decrease in the normal deoxycytidine triphosphate (dCTP) pools, a decreased negative feedback of dCK, and the enhanced phosphorylation of gemcitabine (33-35). 
Table I. Primer sequence and the fragment size of hENT1, dCK, RRM1 and RRM2.

\begin{tabular}{lllc}
\hline Gene & \multicolumn{1}{c}{$\begin{array}{c}\text { Forward primer } \\
\left(5^{\prime}-3^{\prime}\right)\end{array}$} & \multicolumn{1}{c}{$\begin{array}{c}\text { Reverse primer } \\
\left(5^{\prime}-3^{\prime}\right)\end{array}$} & $\begin{array}{c}\text { Fragment } \\
\text { size (bp) }\end{array}$ \\
\hline hENT1 & GCTGCTGTGCAACATTAAGC & AAAGGCAGCCATGAAGAAGA & 87 \\
dCK & TTCCTGAACCTGTTGCCAGAT & GAGACATTGTAAGTTCCTCAAATTCATC & 72 \\
RRM1 & CCTGGGGCATTTGCTATTTA & GCTGCTCTTCCTTTCCTGTG & 93 \\
RRM2 & ATGAAAACTTGGTGGAGCGATT & TGGCAATTTGGAAGCCATAGA & 78 \\
B-actin & CGAGCGCGGCTACAGCTT & TCCTTAATGTCACGCACGATTT & 60 \\
\hline
\end{tabular}

hENT1 is the major transporter of gemcitabine. Cells lacking hENT1 are highly resistant to gemcitabine $(36,37)$, and pancreas cancer patients with hENT1-positive tumor tissue have significantly longer survival after gemcitabine chemotherapy than patients without detectable hENT1 (38). $\mathrm{dCK}$ plays a key role in the activation of gemcitabine, and its activity correlates with the drug sensitivity (39-41). Deficiency in the dCK activity has been considered to be one of the main mechanisms for the development of resistance to gemcitabine (42). Another factor in gemcitabine resistance is the overexpression of RR. RR is a holoenzyme consisting of dimerized RR subunit 1 and 2 (RRM1, RRM2) which is essential for DNA synthesis (43). Increased RRM1 expression and activity has been shown to be a marker for gemcitabine resistance in vitro $(44,45)$.

Thus, gemcitabine has a complex pathway of metabolism, and there are many factors that can contribute to either gemcitabine cytotoxicity or chemoresistance. A gene expression analysis may therefore help the management of cancer patients treating with gemcitabine, thus allowing the selection of subjects responding to the treatment. The present study assessed the expression pattern of 4 key molecules (hENT1, dCK, RRM1 and RRM2) involved in gemcitabine metabolism in BTC, and identify the most useful chemoresistance marker to gemcitabine among the 4 key molecules. We also quantitatively analyzed a gemcitabine resistance marker in clinical samples using quantitative doublefluorescence immunohistochemistry (qDFIHC), which was originally established in our laboratory (46).

\section{Materials and methods}

Cell lines and culture. Three human gall bladder carcinoma cell lines (GB-d1, GBK-1 and KMG-C) and two human bile duct carcinoma cell lines (TFK-1 and HBDC) were used. GB-d1 was provided from Dr T. Date (Kyushu University, Fukuoka, Japan). GBK-1 was provided from Dr H. Egami (Kumamoto University, Kumamoto, Japan). KMG-C was provided from Dr H. Yano (Kurume, Japan). TFK-1 was from the Cell Resource Center for Biomedical Research, Tohoku University (Miyagi, Japan). HBDC was established in our laboratory (47). The cells were cultured in RPMI-1640 medium (Sigma, St. Louis, MO, USA) supplemented with $10 \%$ heat-inactivated fetal bovine serum (FBS) and $100 \mu \mathrm{g} / \mathrm{ml}$ kanamycin (Meiji, Tokyo, Japan) and incubated at $37^{\circ} \mathrm{C}$ in a humidified atmosphere containing $20 \% \mathrm{O}_{2}$ and $5 \% \mathrm{CO}_{2}$ in air.
Clinical samples. Ten tissue samples were obtained from unresectable or recurrent BTC patients who underwent gemcitabine-based chemotherapy at the Department of Surgery, Saga University Hospital (Saga, Japan) from April 2005 to March 2008. Patients with pathologically confirmed unresectable, metastatic or recurrent BTC, and who had at least 1 measurable lesion ( $>2 \mathrm{~cm}$ in longer axis) according to the Response Evaluation Criteria in Solid Tumors (RECIST, National Cancer Institute, Cancer Therapy Evaluation Program), were considered eligible. Informed consent for the use of these specimens was obtained from all patients, and the study protocol was approved by the Ethics Committee of Saga University, Faculty of Medicine.

Total RNA extraction and quantitative reverse transcriptionpolymerase chain reaction. Total RNA was extracted from each cell line using an Isogen RNA extraction kit (Nippon Gene, Osaka, Japan) according to the manufacturer's instructions. For each cell line, $1 \mu \mathrm{g}$ of RNA was converted into cDNA using a ReverTra Ace (Toyobo, Osaka, Japan) reverse transcription reaction kit. The cDNA was used as a template for polymerase chain reaction (PCR). Quantitative reverse transcription (RT)-PCR was performed on a LightCycler $^{\mathrm{TM}}$ instrument system (Roche, Mannheim, Germany) using the Light-Cycler-FastStart DNA Master ${ }^{\mathrm{TM}}$ SYBR Green I kit (Roche) according to the manufacturer's instructions. The primer sequences and the fragment size of each gene are shown in Table I. After a denaturing step at $95^{\circ} \mathrm{C}$ for $3 \mathrm{~min}$, PCR amplification was performed with 50 cycles of $15 \mathrm{sec}$ denaturing at $95^{\circ} \mathrm{C}, 5 \mathrm{sec}$ annealing at $60^{\circ} \mathrm{C}$ and $10 \mathrm{sec}$ extension at $72^{\circ} \mathrm{C}$. We used a melting curve analysis to control for the specificity of the amplification products. The quantitative value was normalized by the $\beta$-actin expression which was used as an internal control. These experiments were all carried out in triplicate and the mean values were calculated.

Chemotherapeutic agent. Gemcitabine was provided from Eli Lilly and Co. (Indianapolis, IN, USA). It was dissolved in RPMI-1640 medium supplemented with $1 \%$ FBS and $100 \mu \mathrm{g} /$ $\mathrm{ml}$ kanamycin, and diluted to the required concentrations immediately before use.

Drug sensitivity test. The cytotoxic effect of gemcitabine treatment in BTC cell lines was assessed by MTT assay using a CellTiter $96^{\mathrm{TM}}$ non-radioactive cell proliferation assay kit 


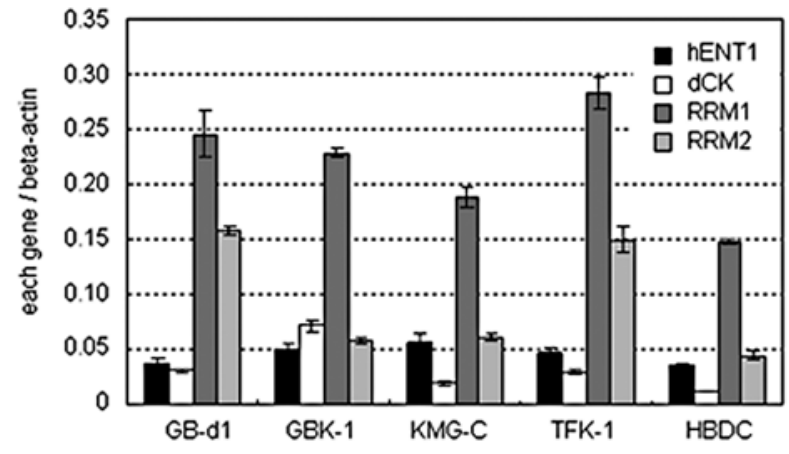

Figure 1. Expression levels of hENT1, dCK, RRM1 and RRM2 in 5 biliary tract carcinoma cell lines. The expression level of RRM1 was the highest among the 4 genes in all 5 cell lines. The quantitative value was normalized by $B$-actin expression used as an internal control. The data represent the mean \pm SD of three independent experiments

(Promega, Madison, WI, USA). In brief, $8 \times 10^{3}$ cells per well were seeded in triplicate onto 96-well plates and cultured for $24 \mathrm{~h}$. The cells were exposed to an increasing concentration of gemcitabine, ranging from $0.1 \mu \mathrm{M}$ to $10 \mathrm{mM}$, for $72 \mathrm{~h}$. The proliferation curves were then constructed by calculating the mean value of the optical density measurements at $590 \mathrm{~nm}$ using a 96-well plate reader (Immuno-mini NJ2300, Nalge Nunc International K.K., Tokyo, Japan).

Western blot analysis. Whole cell lysate from cultured cells was prepared using lysis buffer composed of $150 \mathrm{mM} \mathrm{NaCl}$, $50 \mathrm{mM}$ Tris- $\mathrm{HCl}$ (pH 7.6), $0.5 \%$ Triton X-100 and a protease inhibitor cocktail mix (Roche Diagnostics GmbH, Mannheim, Germany). The samples were dissolved in NuPage ${ }^{\mathrm{TM}}$ LDS sample buffer (Invitrogen, Carlsbad, CA, USA) and $1 \mathrm{M}$ dithiothreitol (DTT), and heated for $5 \mathrm{~min}$ at $95^{\circ} \mathrm{C}$. Aliquots containing $20 \mu \mathrm{g}$ of protein were subjected to NuPage $4-12 \%$ Bis-Tris Gel (Invitrogen) and electrophoretically transferred onto a Hybond ${ }^{\mathrm{TM}}$ nitrocellulose enhanced chemiluminescence membrane (Amersham Pharmacia Biotech, Buckinghamshire, UK) in transfer buffer. The membranes were blocked with $5 \%$ skim milk for $30 \mathrm{~min}$, and incubated with primary antibodies for $2 \mathrm{~h}$ at room temperature. The primary antibodies used in the Western blot analysis were anti-RRM1 (1:500, Chemicon, Temecula, CA, USA), anti-RRM2 (1:500, Santa Cruz Biotechnology, Santa Cruz, CA, USA), and anti- $\beta$-actin (1:10000, Sigma). After incubation with the corresponding secondary antibodies, the signals were developed using an Amersham $^{\text {TM }}$ ECL Plus Western blotting detection system (GE healthcare, Buckinghamshire, UK). The digital images were acquired on a Lunimo-Image analyzer LAS3000 (Fujifilm, Tokyo, Japan), and the quantitative value of the signal intensity was calculated using a computer software Multi Gauge V3.1 (Fujifilm), and then it was normalized by the $\beta$-actin expression which was used as an internal control.

Quantitative double-fluorescence immunohistochemistry (qDFIHC). qDFIHC for RRM1 was performed according to the procedures described in previous studies with slight modifications $(46,48)$. Briefly, paraffin-embedded samples were cut into $4-\mu \mathrm{m}$ sections, and these tissue sections were deparaffinized in xylene and rehydrated in a graded series of ethanols. For antigen retrieval, the tissue sections were treated by microwave boiling in $1 \mathrm{mM}$ EDTA ( $\mathrm{pH} 8.0$ ) for $10 \mathrm{~min}$. The slides were then incubated with $5 \%$ skim milk for $10 \mathrm{~min}$ to block any nonspecific binding of the immunoreagents.

Next, the primary anti-RRM1 antibody (1:200, Chemicon) was placed onto the slides, and the slides were incubated at room temperature for $2 \mathrm{~h}$. After washing in phosphatebuffered saline (PBS), the slides were incubated with fluorescein isothiocyanate (FITC) conjugated secondary antibody (anti-mouse $\mathrm{IgG}, 1: 100$, Invitrogen) at room temperature for $30 \mathrm{~min}$. The slides were then washed and incubated with the primary prediluted anti- $\beta$-actin antibody (Gene Tex, San Antonio, TX, USA) at room temperature for $2 \mathrm{~h}$. After washing, the slides were incubated with a $\mathrm{Cy} 3$ conjugated secondary antibody (anti-rabbit IgG, 1:200, Chemicon) for $30 \mathrm{~min}$. After washing, the slides were mounted with mounting medium (FluoroGurd ${ }^{\mathrm{TM}}$, Bio-Rad Laboratories, Hercules, CA, USA) and then were subjected to Laser scanning microscopy. The digital images of qDFIHC were acquired on a confocal laser scanning microscope LSM5 Pascal (Carl Zeiss Microimaging, Jena, Germany), in which Cy3 (red color for B-actin) was acquired on channel 1, while FITC (green color for RRM1) was acquired on channel 2.

All of the digital images were acquired at x200 magnification, where cancer foci avoiding non-cancerous cells could best be identified. Next, the digital images were analyzed using a computer software LSM image examiner. In each case, the ratio of the total fluorescence intensity of RRM1 (FITC) to B-actin (Cy3) was calculated, and the mean value of 3 fields was considered to be the quantification value.

Statistical analysis. The correlation between $\mathrm{IC}_{50}$ value for gemcitabine and the expression level of each gene or protein in the 5 BTC cell lines was assessed statistically by Pearson's correlation. Differences in the mean values were evaluated by the Student's t-test, and differences in the frequencies were analyzed with Fisher's exact test. The survival curve was calculated by the Kaplan-Meier method and compared by using the log-rank test. $\mathrm{P}<0.05$ were considered to be statistically significant.

\section{Results}

mRNA expression of hENT1, dCK, RRM1 and RRM2. Four genes (hENT1, dCK, RRM1 and RRM2) were selected as candidates for gemcitabine sensitive/resistance marker based on the metabolic pathway of gemcitabine. The expression level of each gene in 5 BTC cell lines was assessed by quantitative RT-PCR, and the result is shown in Fig. 1. In all cell lines, the expression level of RRM1 was the highest among the 4 genes, whereas the expression of hENT1 and $\mathrm{dCK}$ was at a low level in comparison to RR.

Drug sensitivity to gemcitabine in the 5 biliary tract carcinoma cell lines. The drug sensitivity to gemcitabine was assessed by MTT assay. The proliferation curves of 5 cell lines are shown in Fig. 2A. GB-d1 was the most sensitive to gemcitabine; in contrast, TFK-1 was the most resistant to gemcitabine. The $\mathrm{IC}_{50}$ value for gemcitabine in the 5 cell 
A

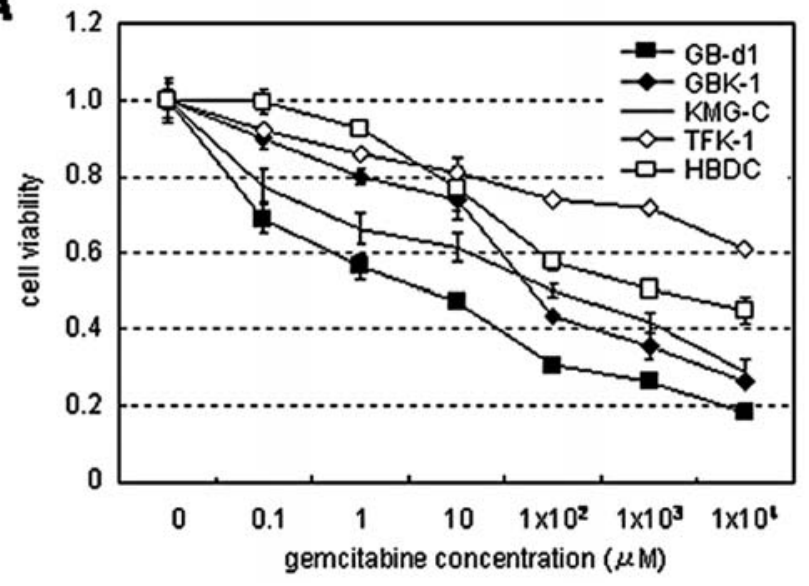

B

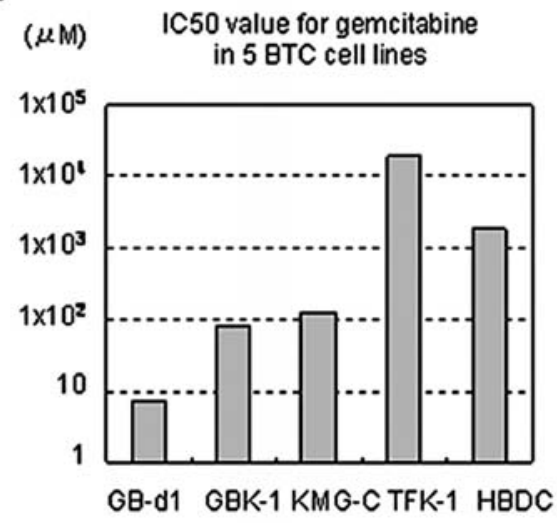

Figure 2. (A) The proliferation curves of 5 cell lines. A sample containing $8 \times 10^{3}$ cells per well were seeded in triplicate onto 96-well plates. All cell lines were treated with $0.1 \mu \mathrm{M}-10 \mathrm{mM}$ of gemcitabine for $72 \mathrm{~h}$. The cell viability value was expressed relative to that of cells without treatment, and the data represent the mean $\pm \mathrm{SD}$. (B) $\mathrm{IC}_{50}$ value for gemcitabine in the 5 cell lines calculated from proliferation curves. The $\mathrm{IC}_{50}$ value in TFK-1 was $\sim 2,600$-fold higher than in GB-d1 (1.91x10 $\mu \mathrm{M}, 7.25 \mu \mathrm{M}$, respectively).

Table II. Correlation between $\mathrm{IC}_{50}$ and each four gene or their combination.

\begin{tabular}{lrcc}
\hline Gene or combination & R-value & $\mathrm{R}^{2}$ & P-value \\
\hline 1/hENT1 & -0.091 & 0.008 & 0.884 \\
1/dCK & -0.114 & 0.013 & 0.885 \\
RRM1 & 0.627 & 0.393 & 0.257 \\
RRM2 & 0.524 & 0.275 & 0.365 \\
1/(hENT1 x dCK) & -0.125 & 0.016 & 0.842 \\
RRM1 x RRM2 & 0.621 & 0.386 & 0.264 \\
(RRM1 x RRM2)/(hENT1 x dCK) & 0.511 & 0.261 & 0.379 \\
\hline
\end{tabular}

Table III. Correlation between $\mathrm{IC}_{50}$ and $\mathrm{RR}$ protein.

\begin{tabular}{lccc}
\hline Protein & R-value & $\mathrm{R}^{2}$ & P-value \\
\hline RRM1 & 0.935 & 0.874 & 0.020 \\
RRM2 & 0.771 & 0.594 & 0.127 \\
\hline
\end{tabular}

lines was calculated based on the result of the MTT assay, and the results are shown in Fig. 2B. The $\mathrm{IC}_{50}$ value in TFK-1 was 2,600 -fold higher than in GB-d1.

Correlation between the expression level of each gene and sensitivity to gemcitabine. The correlation between the mRNA expression of each gene and $\mathrm{IC}_{50}$ value for gemcitabine in the 5 cell lines is shown in Table II. The result shows a tendency for a positive correlation between the expression of RRM1 and the $\mathrm{IC}_{50}$ value $(\mathrm{R}=0.627)$, although this correlation was not statistically significant $(\mathrm{p}=0.257)$. The expression of RRM2 also weakly correlated with the $\mathrm{IC}_{50}(\mathrm{R}=0.520)$. However, the expression of hENT1 and dCK did not correlate with the gemcitabine sensitivity $(R=-0.091,-0.114$,

\section{A}

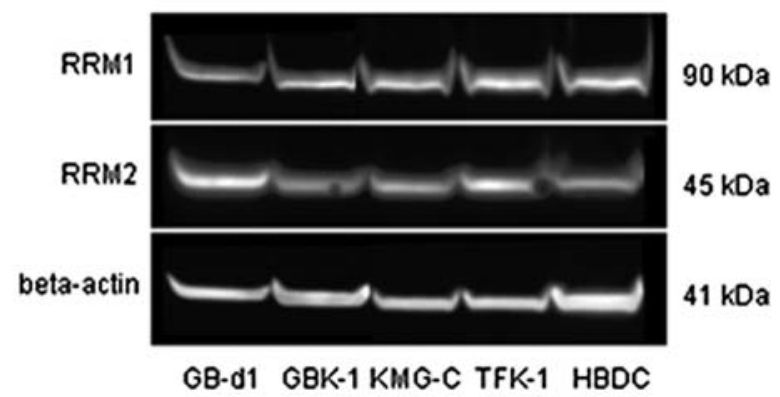

B

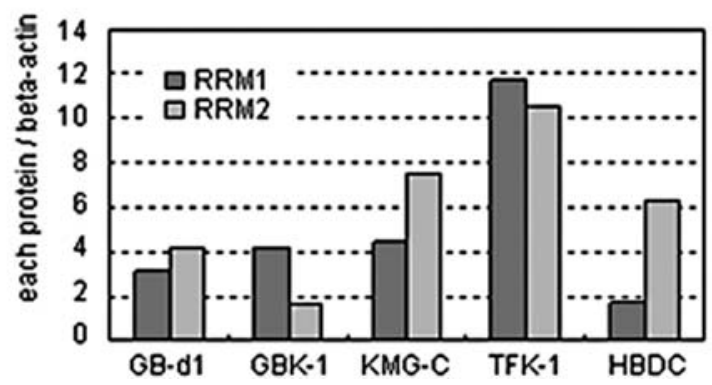

Figure 3. (A) A Western blot analysis of RRM1 and RRM2. Protein $(20 \mu \mathrm{g})$ per sample was loaded, and equal loading was confirmed by using $\beta$-actin as a control. The digital images were acquired on a Lunimo-Image analyzer LAS3000 to quantify the signal intensity. (B) Quantitative values of RRM1 and RRM2 protein adjusted by $\beta$-actin. The quantitative value was calculated using the Multi Gauge V3.1 computer software package.

respectively). Furthermore, the R-values of various combinations of 4 genes were not superior to those of a single RRM1 gene.

Western blot analysis for RRM1 and RRM2. Fig. 3A shows the expression of RRM1 and RRM2 protein in 5 BTC cell lines. The quantitative values of RRM1 and RRM2 protein adjusted by $B$-actin were calculated using digital images acquired on a LAS3000 (Fig. 3B). The correlation between the protein level of $\mathrm{RR}$ and the $\mathrm{IC}_{50}$ value for gemcitabine in 
Table IV. Clinicopathological features and the value of RRM1 quantified by qDFIHC.

\begin{tabular}{cccccccccccc}
\hline Case & Age & Gender & Disease & $\begin{array}{c}\text { Advanced/ } \\
\text { recurrence }\end{array}$ & Histology & Regimen & Radiation & Response & $\begin{array}{c}\text { Outcome } \\
\begin{array}{c}\text { RRM1 } \\
\text { (qDFIHC) }\end{array}\end{array} \begin{array}{c}\text { Survival } \\
\text { (month) }\end{array}$ \\
\hline 1 & 51 & Male & EBDC & Adv & Mod & GEM & + & SD & Dead & 0.88 & 34.9 \\
2 & 55 & Male & BDC & Adv & Well & GEM+FT & + & PR & Dead & 0.96 & 34.8 \\
3 & 78 & Female & IBDC & Adv & - & GEM+FT & - & SD & Dead & 0.98 & 33.6 \\
4 & 76 & Male & IBDC & Rec & Well & GEM & - & SD & Dead & 0.93 & 20.9 \\
5 & 69 & Female & EBDC & Adv & - & GEM & + & SD & Dead & 0.93 & 20.2 \\
6 & 76 & Male & EBDC & Adv & Well & GEM & + & PR & Dead & 0.98 & 18.2 \\
7 & 77 & Male & EBDC & Adv & - & GEM+S-1 & + & SD & Dead & 1.07 & 15.9 \\
8 & 46 & Female & EBDC & Rec & Well & S-1 $\rightarrow$ GEM & - & PD & Dead & 1.13 & 13.0 \\
9 & 74 & Female & GBC & Rec & Well & GEM+S-1 & - & PD & Dead & 0.99 & 9.3 \\
10 & 66 & Male & EBDC & Adv & Mod & GEM+FT & - & PD & Dead & 0.99 & 5.5 \\
\hline
\end{tabular}

IBDC, intra-hepatic bile duct carcinoma; Adv, advanced; FT, tegafur; PD, progressive disease; EBDC, extra-hepatic bile duct carcinoma; Rec, recurrence; PR, partial response; GBC, gall bladder carcinoma; GEM, gemcitabine; SD, stable disease.

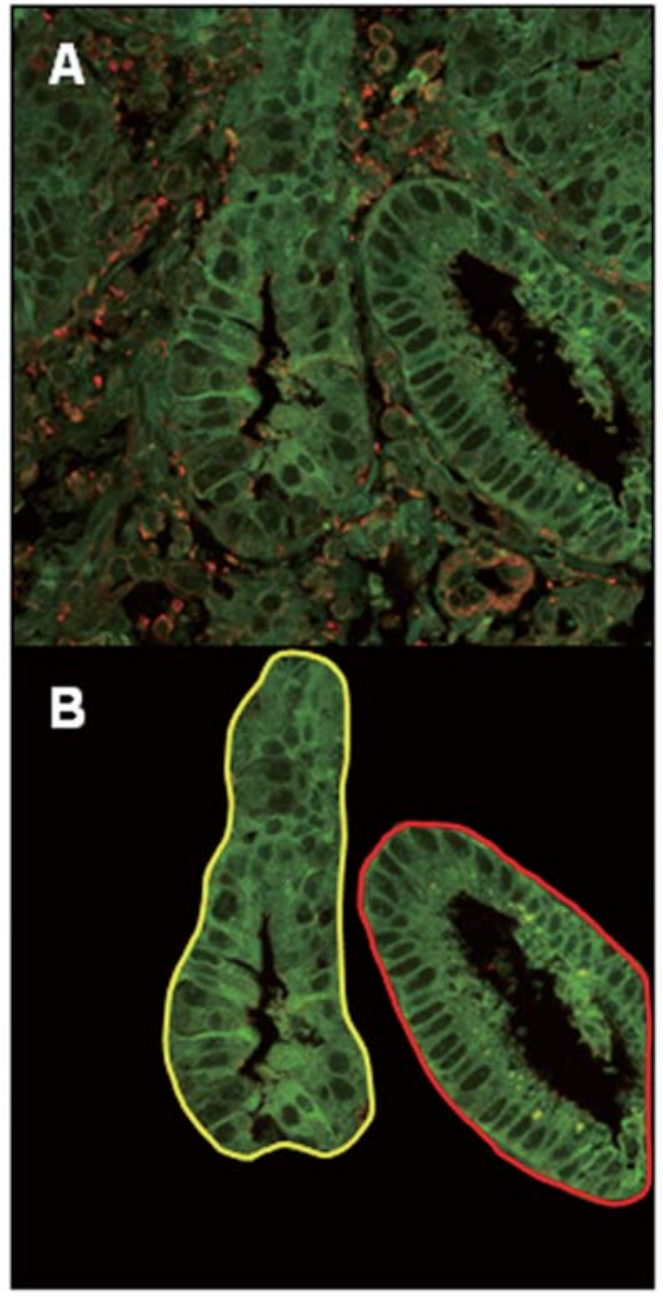

Figure 4. (A) Quantitative double-fluorescence immunohistochemistry for RRM1. The total fluorescence intensity of FITC and Cy3 was acquired on LSM5 Pascal to quantitatively evaluate the RRM1 expression in the field. The ratio of FITC for RRM1/Cy3 for B-actin was calculated and regarded as the relative RRM1 expression in each field, and then the mean value of 3 fields was considered to be the quantification value in each case. (B) RRM1 expression in cancer foci. The expression of RRM1 in stromal tissue was excluded like a microdissection in order to evaluate the cancer-specific expression of RRM1 the 5 cell lines is shown in Table III. The results show a significantly strong correlation between RRM1 protein and the $\mathrm{IC}_{50}$ value for gemcitabine $\left(\mathrm{R}=0.935, \mathrm{R}^{2}=0.874, \mathrm{p}=0.020\right)$. The expression of RRM2 protein also correlated with the $\mathrm{IC}_{50}$ value, although the correlation was weaker than for the expression of RRM1 and not statistically significant $(\mathrm{R}=0.771$, $\left.\mathrm{R}^{2}=0.594, \mathrm{p}=0.127\right)$.

Quantification of RRM1 by qDFIHC in clinical samples. The expression level of RRM1 protein in BTC patients was assessed by quantitative double-fluorescence immunohistochemistry (qDFIHC). We performed qDFIHC staining by FITC (green color) for RRM1 and by $\mathrm{Cy} 3$ (red color) for B-actin (Fig. 4A). As demonstrated in Fig. 4B, the expression of RRM1 protein in stromal tissue was excluded like a microdissection in order to evaluate the cancer-specific expression of RRM1.

Correlation between clinical response to gemcitabine and expression of RRM1. The qDFIHC was used to quantitatively determine the expression of RRM1 in 10 BTC patients. Table IV is a summary of patient characteristics and the values of RRM1 quantified by qDFIHC. All patients received gemcitabine-based chemotherapy with or without radiotherapy. The 10 patients, 6 males and 4 females, were aged from 46 to 78 years (mean: $66.8 \pm 11.9$ years). Of the 10 patients, 3 were diagnosed with intrahepatic bile duct carcinoma, 6 with extra-hepatic bile duct carcinoma, and 1 patient had gall bladder carcinoma. The median follow-up period was 19.2 months (range: 5.5-34.9 months). All patients died from cancer during the follow-up period. The clinical response to chemotherapy was evaluated according to the RECIST criteria and classified into PR (partial response), SD (stable disease), and PD (progressive disease). Furthermore, the patients were divided into 2 groups as follows: disease control group (PR and SD patients) and noncontrol group (PD patients). Table V shows the relationship between patient characteristics and the response to gemcitabine. The expression level of RRM1 was divided into high and 
Table V. Comparison between the effect of gemcitabine and clinicopathological features.

\begin{tabular}{lccc}
\hline Factor & $\begin{array}{c}\text { Control group } \\
(\mathrm{n}=7)\end{array}$ & $\begin{array}{c}\text { Non-control group } \\
(\mathrm{n}=3)\end{array}$ & P-value \\
\hline Age & $68.9 \pm 11.3$ & $62.0 \pm 14.4$ & $\mathrm{NS}$ \\
Gender & & 1 & \\
$\quad \begin{array}{l}\text { Male } \\
\text { Female }\end{array}$ & 5 & 2 & $\mathrm{NS}$ \\
Histology & 2 & 2 & \\
$\quad$ Well & 3 & 1 & $\mathrm{NS}$ \\
Mod & 1 & & $\mathrm{NS}$ \\
Radiation & & 0 & \\
+ & 5 & 3 & $0.033^{\mathrm{c}}$ \\
- & 2 & 3 & \\
RRM1 & & & \\
High & 1 & & \\
(qDFIHC) & & & \\
Low & 6 & & \\
\hline
\end{tabular}

${ }^{\mathrm{a} C}$ Control group, PR and SD patients; ${ }^{\mathrm{b}}$ Non-control group, PD

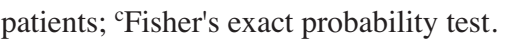

low, with the mean value of all cases $(0.984 \pm 0.072)$ as a cut-off value. Although no significant differences were observed regarding age, gender, histology, and radiotherapy, the patients with a low RRM1 expression were significantly more sensitive to gemcitabine than those with a high RRM1 expression $(\mathrm{p}=0.033)$.

Patient survival according to the expression of RRM1. The relationship between the patient survival and the expression level of RRM1 was statistically analyzed by Kaplan-Meier method. The survival of patients with a low RRM1 expression $(n=6)$ was significantly better than that of the patients with a high RRM1 expression $(n=4)(P=0.001)$ (Fig. 5).

\section{Discussion}

Biliary tract carcinoma (BTC) is one of the most aggressive human malignancies, in which only surgical resection offers the opportunity for cure (2-4). Unresectable and recurrent BTC patients have a very poor prognosis, and these patients will receive palliative chemotherapy. Gemcitabine has been commonly used as a chemotherapeutic agent for advanced BTC. However, the efficacy of this drug for advanced BTC is insufficient with a response rate of $\sim 30 \%$ (6-10). Therefore, new strategies, such as combination with other drugs or a molecular approach, which allows the selection of responders, are necessary, in order to improve patient outcome.

Several molecules including ABCC5 (49), c-Src (50), BNIP3 (51) and focal adhesion kinase (FAS) (52) have been reported to be a gemcitabine sensitive/resistance marker.

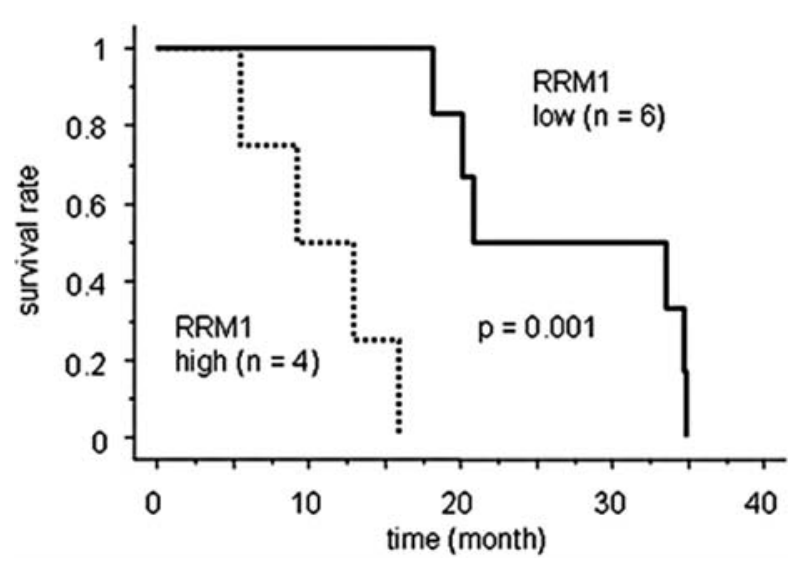

Figure 5. Kaplan-Meier estimates of the patients' survival according to the expression of RRM1. Patients with a low RRM1 expression showed a significantly longer survival than the patients with a high RRM1 expression.

Other in vitro studies have demonstrated that the expression of 4 molecules (hENT1, dCK, RRM1 and RRM2), which are involved in gemcitabine metabolism, can determine the efficacy of gemcitabine $(36,37,42,44,45)$. Furthermore, two clinical studies have demonstrated that the assessment of hENT1 and RRM1 is useful in order to predict the response to gemcitabine in pancreas and lung cancer, respectively $(38,53)$. Our previous study has also indicated the importance of RRM1 as a possible chemoresistance marker for gemcitabine in BTC (48). However, despite the numerous investigations to elucidate the mechanism of gemcitabine efficacy, no reliable marker has yet been identified. Therefore, it is necessary to establish new diagnostic methods, which can accurately predict the response to gemcitabine, in order to perform tailored chemotherapy for BTC patients.

The present study initially investigated the expression of 4 candidate genes for gemcitabine sensitive/resistance markers in 5 BTC cell lines. The mRNA level of RRM1 correlated with the $\mathrm{IC}_{50}$ value for gemcitabine $(\mathrm{R}=0.627)$ and $\mathrm{RRM} 2$ also showed a slight correlation with the $\mathrm{IC}_{50}$ value $(\mathrm{R}=0.520)$ (Table II). Furthermore, both RRM1 and RRM2 protein were more strongly correlated with gemcitabine resistance than the mRNA levels, although the relationship between RRM2 protein and the $\mathrm{IC}_{50}$ value for gemcitabine was not statistically significant (Table III). In contrast, neither hENT1 nor dCK were correlated with gemcitabine sensitivity. The expression of hENT1 and dCK in these cell lines might be too low to determine the response to gemcitabine. dCK expression is usually down-regulated by increased RRM1 expression via negative feedback pathways. In addition, several transporters other than hENT1, such as hENT2, hCNT1 and hCNT3, also regulate the uptake of gemcitabine (30). García-Manteiga et al demonstrated that hCNT1 determines the sensitivity to gemcitabine in pancreatic cancer cells which overexpress hENT1 (54).

Another study demonstrated that the expression of hENT1, dCK, RRM1 and RRM2 is not correlated with gemcitabine sensitivity, although the ratio of the expression level of the 4 genes correlates with gemcitabine resistance in pancreatic cancer cells (55). It might be difficult to determine the sensitivity to gemcitabine with a single factor, since many 
factors contribute to the regulation of gemcitabine efficacy. This study also assessed the various combinations of these 4 genes in order to investigate the useful predictive index of gemcitabine. However, the single expression of RRM1 showed the strongest correlation with the $\mathrm{IC}_{50}$ value for gemcitabine (Table II). RRM1 particularly in protein level is, therefore, considered to be the most reliable marker for gemcitabine resistance in BTC cell lines.

The expression of RRM1 protein was also assessed by qDFIHC in 10 patients with unresectable or recurrent BTC, as a pilot study, in order to validate the role of RRM1 in resistance to gemcitabine. This method, reported by us in 2007 (46), is a novel technique, which allows the quantification of protein even in tiny formalin-fixed paraffin embedded samples such as biopsy specimens. Moreover, using this method, a target protein can be easily quantified with avoiding non-cancerous tissues by surrounding cancer foci on a digital image such as a microdissection (Fig. 4B). The reliability of the qDFIHC method was initially evaluated by comparison with Western blot analysis. The expression of RRM1 protein quantified by qDFIHC is almost the same as that of Western blot analysis in 5 BTC cell lines $(R=0.868$, $\mathrm{P}=0.035$, data not shown). The result obtained from this method is, therefore, considered to be available as a quantitative value of RRM1 protein. The result of qDFIHC demonstrated that patients with low RRM1 were significantly more sensitive to gemcitabine than those with high RRM1 (Table V). In addition, the survival of patients with low RRM1 was significantly longer than those with high RRM1 (Fig. 5). A study using a larger number of patients will be necessary to increase the reliability of our data since only 10 patients were enrolled in the present study.

It is usually difficult to obtain large clinical samples, which is needed for a conventional protein expression assay, from unresectable or recurrent BTC patients. In contrast, qDFIHC requires only a small amount of cancer tissue. Therefore, biopsy samples, obtained by the endoscopic approach or the exploratory laparoscopy, are sufficient. Thus, the assessment of RRM1 in cancer tissue by qDFIHC might be useful for the selection of patients who will benefit from gemcitabine-based chemotherapy.

In conclusion, among the several molecules involved in the gemcitabine metabolism, RRM1 particularly the level of protein expression is the most reliable marker for gemcitabine resistance in BTC cell lines. Furthermore, qDFIHC, which allows the quantification of cancer-specific expression of a target protein even in the biopsy specimens, is useful for the assessment of RRM1 protein in order to design a tailor-made chemotherapeutic regimen for BTC patients.

\section{References}

1. Ministry of Health, Labour and Welfare. Statistics and Information Department, Minister's Secretariat, Ministry of Health, Labour and Welfare: Vital Statistics in Japan, 2000 (in Japanese).

2. Pichlmayr R, Lamesch P, Weimann A, Tusch G and Ringe B: Surgical treatment of cholangiocellular carcinoma. World J Surg 19: 83-88, 1995

3. Valverde A, Bonhomme N, Farges O, Sauvanet A, Flejou JF and Belghiti J: Resection of intrahepatic cholangiocarcinoma: a Western experience. J Hepatobiliary Pancreat Surg 6: 122-127, 1999.
4. de Groen PC, Gores GJ, LaRusso NF, Gunderson LL and Nagorney DM: Biliary tract cancers. N Engl J Med 341: 1368-1378, 1999.

5. Glimelius B, Hoffman K, Sjödén PO, Jacobsson G, Sellström H, Enander LK, Linné T and Svensson C: Chemotherapy improves survival and quality of life in advanced pancreatic and biliary cancer. Ann Oncol 7: 593-600, 1996.

6. Gebbia V, Giuliani F, Maiello E, Colucci G, Verderame F, Borsellino N, Mauceri G, Caruso M, Tirrito ML and Valdesi M: Treatment of inoperable and/or metastatic biliary tree carcinomas with single-agent gemcitabine or in combination with levofolinic acid and infusional fluorouracil: results of a multicenter phase II study. J Clin Oncol 19: 4089-4091, 2001

7. Penz M, Kornek GV, Raderer M, Ulrich-Pur H, Fiebiger W, Lenauer A, Depisch D, Krauss G, Schneeweiss B and Scheithauer W: Phase II trial of two-weekly gemcitabine in patients with advanced biliary tract cancer. Ann Oncol 12: 183-186, 2001

8. Park JS, Oh SY, Kim SH, Kwon HC, Kim JS, Jin-Kim H and Kim YH: Single-agent gemcitabine in the treatment of advanced biliary tract cancers: a phase II study. Jpn J Clin Oncol 35: 68-73, 2005.

9. Okusaka T, Ishii H, Funakoshi A, Yamao K, Ohkawa S, Saito S, Saito $\mathrm{H}$ and Tsuyuguchi T: Phase II study of single-agent gemcitabine in patients with advanced biliary tract cancer. Cancer Chemother Pharmacol 57: 647-653, 2006

10. Valle JW, Wasan H, Johnson P, Jones E, Dixon L, Swindell R, Baka S, Maraveyas A, Corrie P, Falk S, Gollins S, Lofts F, Evans L, Meyer T, Anthoney A, Iveson T, Highley M, Osborne R and Bridgewater J: Gemcitabine alone or in combination with cisplatin in patients with advanced or metastatic cholangiocarcinomas or other biliary tract tumours: a multicentre randomised phase II study - The UK ABC-01 Study. Br J Cancer 101: 621-627, 2009.

11. Patt YZ, Hassan MM, Aguayo A, Nooka AK, Lozano RD, Curley SA, Vauthey JN, Ellis LM, Schnirer II, Wolff RA, Charnsangavej $\mathrm{C}$ and Brown TD: Oral capecitabine for the treatment of hepatocellular carcinoma, cholangiocarcinoma, and gallbladder carcinoma. Cancer 101: 578-586, 2004.

12. Androulakis N, Aravantinos G, Syrigos K, Polyzos A, Ziras N, Tselepatiotis E, Samonis G, Kentepozidis N, Giassas S, Vamvakas L and Georgoulias V: Oxaliplatin as first-line treatment in inoperable biliary tract carcinoma: a multicenter phase II study. Oncology 70: 280-284, 2006.

13. Ueno H, Okusaka T, Ikeda M, Takezako Y and Morizane C: Phase II study of S-1 in patients with advanced biliary tract cancer. Br J Cancer 91: 1769-1774, 2004.

14. Furuse J, Okusaka T, Boku N, Ohkawa S, Sawaki A, Masumoto T and Funakoshi A: S-1 monotherapy as first-line treatment in patients with advanced biliary tract cancer: a multicenter phase II study. Cancer Chemother Pharmacol 62: 849-855, 2008.

15. Knox JJ, Hedley D, Oza A, Feld R, Siu LL, Chen E, Nematollahi M, Pond GR, Zhang J and Moore MJ: Combining gemcitabine and capecitabine in patients with advanced biliary cancer: a phase II trial. J Clin Oncol 23: 2332-2338, 2005.

16. Riechelmann RP, Townsley CA, Chin SN, Pond GR and Knox JJ: Expanded phase II trial of gemcitabine and capecitabine for advanced biliary cancer. Cancer 110: 1307-1312, 2007.

17. Koeberle D, Saletti P, Borner M, Gerber D, Dietrich D, Caspar CB, Mingrone W, Beretta K, Strasser F, Ruhstaller T, Mora $\mathrm{O}$ and Herrmann R; Swiss Group for Clinical Cancer Research: Patient-reported outcomes of patients with advanced biliary tract cancers receiving gemcitabine plus capecitabine: a multicenter, phase II trial of the Swiss Group for Clinical Cancer Research. J Clin Oncol 26: 3702-3708, 2008.

18. André T, Tournigand C, Rosmorduc O, Provent S, MaindraultGoebel F, Avenin D, Selle F, Paye F, Hannoun L, Houry S, Gayet B, Lotz JP, de Gramont A and Louvet C; GERCOR Group: Gemcitabine combined with oxaliplatin (GEMOX) in advanced biliary tract adenocarcinoma: a GERCOR study. Ann Oncol 15: 1339-1343, 2004.

19. Harder J, Riecken B, Kummer O, Lohrmann C, Otto F, Usadel H, Geissler M, Opitz O and Henss H: Outpatient chemotherapy with gemcitabine and oxaliplatin in patients with biliary tract cancer. Br J Cancer 95: 848-852, 2006.

20. Wagner AD, Buechner-Steudel P, Moehler M, Schmalenberg H, Behrens R, Fahlke J, Wein A, Behl S, Kuss O, Kleber G and Fleig WE: Gemcitabine, oxaliplatin and 5-FU in advanced bile duct and gallbladder carcinoma: two parallel, multicentre phaseII trials. Br J Cancer 101: 1846-1852, 2009. 
21. Nehls O, Oettle H, Hartmann JT, Hofheinz RD, Hass HG, Horger MS, Koppenhöfer U, Hochhaus A, Stieler J, Trojan J, Gregor M and Klump B: Capecitabine plus oxaliplatin as firstline treatment in patients with advanced biliary system adenocarcinoma: a prospective multicentre phase II trial. Br J Cancer 98: 309-315, 2008.

22. Park SH, Park YH, Lee JN, Bang SM, Cho EK, Shin DB and Lee JH: Phase II study of epirubicin, cisplatin, and capecitabine for advanced biliary tract adenocarcinoma. Cancer 106: 361-365, 2006.

23. Kim YJ, Im SA, Kim HG, Oh SY, Lee KW, Choi IS, Oh DY, Lee SH, Kim JH, Kim DW, Kim TY, Kim SW, Heo DS, Yoon YB and Bang YJ: A phase II trial of S-1 and cisplatin in patients with metastatic or relapsed biliary tract cancer. Ann Oncol 19: 99-103, 2008

24. Sasaki T, Isayama $\mathrm{H}$, Nakai $\mathrm{Y}$, Ito $\mathrm{Y}$, Kogure $\mathrm{H}$, Togawa $\mathrm{O}$, Toda N, Yasuda I, Hasebe O, Maetani I, Sasahira N, Hirano K, Tsujino T, Tada M and Omata M: Multicenter, phase II study of gemcitabine and S-1 combination chemotherapy in patients with advanced biliary tract cancer. Cancer Chemother Pharmacol 65: 1101-1107, 2010.

25. Kaye SB: Gemcitabine: current status of phase I and II trials. J Clin Oncol 12: 1527-1531, 1994.

26. Galmarini CM, Mackey JR and Dumontet C: Nucleoside analogues and nucleobases in cancer treatment. Lancet Oncol 3: 415-424, 2002

27. Schiller JH, Harrington D, Belani CP, Langer C, Sandler A, Krook J, Zhu J and Johnson DH; Eastern Cooperative Oncology Group: Comparison of four chemotherapy regimens for advanced non-small-cell lung cancer. N Engl J Med 346: 92-98, 2002.

28. Burris HA III, Moore MJ, Andersen J, Green MR, Rothenberg ML, Modiano MR, Cripps MC, Portenoy RK, Storniolo AM, Tarassoff P, Nelson R, Dorr FA, Stephens CD and Von Hoff DD: Improvements in survival and clinical benefit with gemcitabine as first-line therapy for patients with advanced pancreas cancer: a randomized trial. J Clin Oncol 15: 2403-2413, 1997.

29. Albain KS, Nag SM, Calderillo-Ruiz G, Jordaan JP, Llombart AC, Pluzanska A, Rolski J, Melemed AS, Reyes-Vidal JM, Sekhon JS Simms L and O'Shaughnessy J: Gemcitabine plus Paclitaxel versus Paclitaxel monotherapy in patients with metastatic breast cancer and prior anthracycline treatment. J Clin Oncol 26: 3950-3957, 2008

30. Damaraju VL, Damaraju S, Young JD, Baldwin SA, Mackey J, Sawyer MB and Cass CE: Nucleoside anticancer drugs: the role of nucleoside transporters in resistance to cancer chemotherapy. Oncogene 22: 7524-7536, 2003.

31. Bergman AM, Pinedo HM and Peters GJ: Determinants of resistance to 2',2'-difluorodeoxycytidine (gemcitabine). Drug Resist Updat 5: 19-33, 2002.

32. Huang P, Chubb S, Hertel LW, Grindey GB and Plunkett W: Action of 2',2'-difluorodeoxycytidine on DNA synthesis. Cancer Res 51: 6110-6117, 1991

33. Heinemann V, Schulz L, Issels RD and Plunkett W: Gemcitabine: a modulator of intracellular nucleotide and deoxynucleotide metabolism. Semin Oncol 22 (Suppl 11): 11-18, 1995.

34. Heinemann V, Xu YZ, Chubb S, Sen A, Hertel LW, Grindey GB and Plunkett W: Inhibition of ribonucleotide reduction in CCRF-CEM cells by 2',2'-difluorodeoxycytidine. Mol Pharmacol 38: 567-572, 1990

35. Bergman AM, Pinedo HM, Jongsma AP, Brouwer M, Ruiz van Haperen VW, Veerman G, Leyva A, Eriksson S and Peters GJ: Decreased resistance to gemcitabine $(2$ ',2'-difluorodeoxycitidine) of cytosine arabinoside-resistant myeloblastic murine and rat leukemia cell lines: role of altered activity and substrate specificity of deoxycytidine kinase. Biochem Pharmacol 57: 397-406, 1999

36. Mackey JR, Mani RS, Selner M, Mowles D, Young JD, Belt JA, Crawford CR and Cass CE: Functional nucleoside transporters are required for gemcitabine influx and manifestation of toxicity in cancer cell lines. Cancer Res 58: 4349-4357, 1998.

37. Achiwa H, Oguri T, Sato S, Maeda H, Niimi T and Ueda R: Determinants of sensitivity and resistance to gemcitabine: the roles of human equilibrative nucleoside transporter 1 and deoxycytidine kinase in non-small cell lung cancer. Cancer Sci 95: 753-757, 2004.

38. Spratlin J, Sangha R, Glubrecht D, Dabbagh L, Young JD, Dumontet C, Cass C, Lai R and Mackey JR: The absence of human equilibrative nucleoside transporter 1 is associated with reduced survival in patients with gemcitabine-treated pancreas adenocarcinoma. Clin Cancer Res 10: 6956-6961, 2004.
39. Johansson M, Brismar S and Karlsson A: Human deoxycytidine kinase is located in the cell nucleus. Proc Natl Acad Sci USA 94: 11941-11945, 1997.

40. Sabini E, Ort S, Monnerjahn C, Konrad M and Lavie A: Structure of human dCK suggests strategies to improve anticancer and antiviral therapy. Nat Struct Biol 10: 513-519, 2003.

41. Kroep JR, Loves WJ, van der Wilt CL, Alvarez E, Talianidis I, Boven E, Braakhuis BJ, van Groeningen CJ, Pinedo HM and Peters GJ: Pretreatment deoxycytidine kinase levels predict in vivo gemcitabine sensitivity. Mol Cancer Ther 1: 371-376, 2002.

42. Ruiz van Haperen VW, Veerman G, Eriksson S, Boven E Stegmann AP, Hermsen M, Vermorken JB, Pinedo HM and Peters GJ: Development and molecular characterization of a $2^{\prime}, 2^{\prime}$-difluorodeoxycytidine-resistant variant of the human ovarian carcinoma cell line A2780. Cancer Res 54: 4138-4143, 1994.

43. Cory JG and Sato A: Regulation of ribonucleotide reductase activity in mammalian cells. Mol Cell Biochem 53-4: 257-266, 1983.

44. Goan YG, Zhou B, Hu E, Mi S and Yen Y: Overexpression of ribonucleotide reductase as a mechanism of resistance to 2,2-difluorodeoxycytidine in the human KB cancer cell line. Cancer Res 59: 4204-4207, 1999.

45. Davidson JD, Ma L, Flagella M, Geeganage S, Gelbert LM and Slapak CA: An increase in the expression of ribonucleotide reductase large subunit 1 is associated with gemcitabine resistance in non-small cell lung cancer cell lines. Cancer Res 64: 3761-3776, 2004.

46. Kai K, Kitajima Y, Hiraki M, Satoh S, Tanaka M, Nakafusa Y, Tokunaga $\mathrm{O}$ and Miyazaki K: Quantitative double-fluorescence immunohistochemistry (qDFIHC), a novel technology to assess protein expression: a pilot study analyzing 5-FU sensitive markers thymidylate synthase, dihydropyrimidine dehydrogenase and orotate phosphoribosyl transferases in gastric cancer tissue specimens. Cancer Lett 258: 45-54, 2007.

47. Jiao W, Yakushiji H, Kitajima Y, Ogawa A and Miyazaki K: Establishment and characterization of human hilar bile duct carcinoma cell line and cell strain. J Hepatobiliary Pancreat Surg 7: 417-425, 2000.

48. Ohtaka K, Kohya N, Sato K, Kitajima Y, Ide T, Mitsuno M and Miyazaki K: Ribonucleotide reductase subunit M1 is a possible chemoresistance marker to gemcitabine in biliary tract carcinoma. Oncol Rep 20: 279-286, 2008.

49. Oguri T, Achiwa H, Sato S, Bessho Y, Takano Y, Miyazaki M, Muramatsu H, Maeda H, Niimi T and Ueda R: The determinants of sensitivity and acquired resistance to gemcitabine differ in non-small cell lung cancer: a role of ABCC5 in gemcitabine sensitivity. Mol Cancer Ther 5: 1800-1806, 2006.

50. Duxbury MS, Ito H, Zinner MJ, Ashley SW and Whang EE: Inhibition of SRC tyrosine kinase impairs inherent and acquired gemcitabine resistance in human pancreatic adenocarcinoma cells. Clin Cancer Res 10: 2307-2318, 2004.

51. Akada M, Crnogorac-Jurcevic T, Lattimore S, Mahon P, Lopes R, Sunamura M, Matsuno S and Lemoine NR: Intrinsic chemoresistance to gemcitabine is associated with decreased expression of BNIP3 in pancreatic cancer. Clin Cancer Res 11: 3094-3101, 2005.

52. Duxbury MS, Ito H, Benoit E, Zinner MJ, Ashley SW and Whang EE: RNA interference targeting focal adhesion kinase enhances pancreatic adenocarcinoma gemcitabine chemosensitivity. Biochem Biophys Res Commun 311: 786-792, 2003.

53. Rosell R, Felip E, Taron M, Majo J, Mendez P, Sanchez-Ronco M, Queralt C, Sanchez JJ and Maestre J: Gene expression as a predictive marker of outcome in stage IIB-IIIA-IIIB non-small cell lung cancer after induction gemcitabine-based chemotherapy followed by resectional surgery. Clin Cancer Res 10: S4215-S4219, 2004.

54. García-Manteiga J, Molina-Arcas M, Casado FJ, Mazo A and Pastor-Anglada M: Nucleoside transporter profiles in human pancreatic cancer cells: role of hCNT1 in $2^{\prime}, 2^{\prime}$-difluorodeoxycytidine-induced cytotoxicity. Clin Cancer Res 9: 5000-5008, 2003.

55. Nakano Y, Tanno S, Koizumi K, Nishikawa T, Nakamura K, Minoguchi M, Izawa T, Mizukami Y, Okumura T and Kohgo Y: Gemcitabine chemoresistance and molecular markers associated with gemcitabine transport and metabolism in human pancreatic cancer cells. Br J Cancer 96: 457-463, 2007. 